\title{
DETECTION AND CHARACTERIZATION OF MICROBES CAUSING STUNTED GROWTH IN COMMERCIAL BROILERS
}

\author{
M. M. Shah, M. M. Rahman, M. R. Akter and R. A. Romey \\ Department of Microbiology, Faculty of Veterinary and Animal Science, Hajee Mohammad Danesh Science and \\ Technology University, Dinajpur-5200, Bangladesh.
}

\begin{abstract}
The study was conducted to isolate and characterize the microbes causing stunted growth in commercial broilers from VaiVai Poultry Farm (Kornai, Katapara, Dinajpur), Israfil Poultry Farm (Basherhat, Dinajpur), Guljar Poultry Farm (North Sibrampur, Dinajpur) and Maa Poultry Farm (Nayanpur, Dinajpur), during the period from January 2011 to July 2011. A total of 158 samples comprising dead birds, sick birds, litter, droppings, poultry feed and drinking water were collected among them $56(n=56)$ positive samples were isolated for this study from commercial broilers and subjected to primary isolation by propagating in nutrient broth followed by culture on selective media- Brilliant Green Agar, Salmonella-Shigella Agar, Eosin Methylene Blue Agar and Sabouraud's Dextrose Agar media. Gram's staining techniques were performed. Biochemical properties of the isolates were studied and reaction in TSI agar slant was also observed. Among the 56 positive isolates 9 isolates were found positive for Fungi, 37 isolates were found positive for E. coli and 26 isolates were found to be positive for Salmonella spp. that are the casual factors for stunted growth in commercial broilers. Among them 16 isolates were found mixed infection with Salmonella spp. and E. coli also included in both prevalence. The prevalence of Fungi, E. coli and Salmonella spp. were recorded as $16.07 \%, 66.07 \%$ and $46.42 \%$ respectively. Among the microbes isolated Escherichia coli was determined as predominant bacteria $(66.07 \%)$ causing stunted growth in commercial broilers than Salmonella spp. (46.42\%) and Fungi (16.07\%). Litter and dropping samples were the highest sources of contamination than tracheal swabs. Fungal samples were isolated from feed, litter and drinking water samples and the prevalence of Fungi were recorded as lowest (16.07\%) than other microbes causing stunted growth than Escherichia coli (66.07\%) and Salmonella spp. (46.42\%).
\end{abstract}

Key words: Microbes, stunted growth, commercial broilers.

\section{INTRODUCTION}

Bangladesh is an agricultural country with a large number of domestic chickens and ducks. It is estimated that there are about 153 million chickens and about one lac poultry farms in Bangladesh (Samad, 2005). The commercial broiler and layer farms supplying about 0.2 million metric ton of poultry meat and 5210 million table eggs per year in Bangladesh (Samad, 2005). Poultry is essential to the national economy of Bangladesh and the welfare of human beings as well. The advancement of poultry industry in Bangladesh is interrupted by a number of constraints of which major one is outbreak of disease causing about $30 \%$ mortality of chickens in every year (Ali et al., 2004). Several constrains like diseases, poor husbandry, low productivity and shortage of food affect the optimal performance of this industry in Bangladesh (Haque et al., 1991). The major causes are microorganisms, parasites, managemental causes, environmental causes and deficiency of mineral and vitamins. Organisms involved mainly E. coli, Salmonella and fungus. Avian colibacillosis has been noticed to be a major infectious disease in birds of all ages and has an important economic impact on poultry production worldwide. The majority of economic losses results from mortality and decrease in productivity of the affected birds (Otaki et al., 1995). Salmonella infection caused by a variety of Salmonella species is one of the most important bacterial diseases in poultry causing heavy economic losses through mortality and reduced production (Haider $e t$ al., 2004). Fungi cause significant poultry ailments in Bangladesh. Poor management and lack of knowledge is the main causes of lowering the production and higher the mortality rate in commercial broiler farms. In broiler farms in Bangladesh there are nearly 4.27\% Aspergillosis, $0.52 \%$ Aflatoxicosis which produces toxicity in commercial broiler feed (Saleque et al., 2003). Aspergillus spp is the most common fungi found in air or litter of poultry houses (Scurter et al., 1981). Microbes that are responsible for stunted growth in commercial broilers have been described with their detection and characterization in this paper.

*Corresponding e-mail address: drmamunshah@gmail.com

Copyright (C) 2012 Bangladesh Society for Veterinary Medicine

All rights reserved 0242/2012 


\section{M. Shah and others}

\section{MATERIALS AND METHODS}

This study was conducted during the period from January to July, 2011 in the Microbiology laboratory of the Department of Microbiology, Hajee Mohammad Danesh Science and Technology University (HSTU), Dinajpur. Samples were collected from dead birds, sick birds, litter, droppings, poultry feed and drinking water from selected commercial broiler farms at Dinajpur district in Bangladesh. The experimental birds were Cobb 500 strain and standard body weight of broiler were collected from Nourish Poultry and Hatchery Ltd. (Table 1) Body weight of birds were taken regularly and compared with standard growth, poor body weight or stunted birds were selected for sample collection. Mortality rate also compared with standard rate $\leq 5 \%$ (Nourish Poultry and Hatchery Ltd.) and Guljar Poultry farm was selected randomly for study due to high mortality rate (8\% mortality) (Table 4). Collected samples were undertaken for the isolation and identification of causal agent by morphology, staining and cultural characteristics. Characterizations of isolates were done by biochemical properties.

Table 1. Standard Body weight of Broiler

\begin{tabular}{|lcc|}
\hline S/N & Age of Birth & Body weight (grams) \\
\hline 01. & $1-7^{\text {th }}$ day & $160-170$ \\
02. & $1-14^{\text {th }}$ day & $402-417$ \\
03. & $1-21^{\text {st }}$ day & $725-745$ \\
04. & $1-28^{\text {th }}$ day & $1017-1057$ \\
05. & $1-35^{\text {th }}$ day & $1579-1634$ \\
\hline
\end{tabular}

Source: Nourish Poultry and Hatchery Ltd.

\section{Collection of samples}

The samples were collected from sick and dead birds (tracheal swab, liver, cloal swab, intestinal content and dropping for bacteriological samples), feed, drinking water and litter (for mycological samples) from Vai-Vai Poultry Farm, Israfil Poultry Farm, Guljar Poultry Farm and Maa Poultry Farm. The samples were collected aseptically into a sterile petridis and brought to the laboratory of Microbiology, HSTU, Dinajpur. A total of 56 Broiler birds from 158 samples were tested for the examination for microorganism. Guljar Poultry Farm was selected randomly for study due to high mortality rate ( $8 \%$ mortality) (Table 4$)$. On the other hand different feed samples (starter and finisher) from Guljar Poultry Farm, drinking water samples and litter sample also tested for detection of fungi in Sabouraud's Dextrose Agar media. Total flock size was 2800 from 4 farms (Table 2) among them Guljar Poultry Farm of total flock size was 700 selected randomly for positive isolates.

Table 2. List of the poultry farms for sample collection

\begin{tabular}{|clccc|}
\hline S/ N & Name of the Broiler Farm & Total No. of birds & $\begin{array}{c}\text { No. of collected } \\
\text { samples }\end{array}$ & $\begin{array}{c}\text { Total No. of collected } \\
\text { samples }\end{array}$ \\
\hline 01. & Vai-Vai Poultry Farm & 900 & 39 & 158 \\
02. & Israfil Poultry Farm & 600 & 35 & \\
03. & Guljar Poultry Farm & 700 & 56 \\
04. & Maa Poultry Farm & 600 & 28
\end{tabular}

\section{Isolation and identification of causal agent}

Isolation and characterization of E. coli and Salmonella were performed as per procedure described by Merchant and Packer (1967) and Cowan (1985). E. coli and Salmonella samples were isolated from collected samples by sterilized inoculating loop. Primary culture was performed on nutrient agar. Subcultures were performed in MacConkey (MC) agar, Eosin Methylene Blue (EMB) agar, Simmons citrate agar and SalmonellaShigella (SS) agar to get pure culture and cultural characteristics. 
Microbes causing stunted growth in commercial broilers

\section{Morphological characteristics}

The E. coli and Salmonella organisms were stained by Gram's stain Merchant and Packer (1967). Motility test was performed by MIU (Motility, Indole, Urea) medium according to procedure describe by Cowan (1985).

\section{Biochemical test}

Biochemical tests such sugar fermentation test, Triple Sugar Iron (TSI) agar slant reaction, Indole test, Methyl Red (MR) test, and Voges-Proskauer (VP) test were performed according to the procedure described by Merchant and Packer (1967) and Cowan (1985).

\section{Collection and culture of fungal samples}

Samples were collected from sick birds, dead birds, litter, droppings, poultry feed and drinking water from the different broiler farm and brought to the Laboratory, Department of Microbiology, Hajee Mohammad Danesh Science and Technology University. Primary culture was performed on nutrient agar. Subcultures were performed in Sabouraud's Dextrose Agar (SDA) procedure described by Rippon (1988) and Chowdhury et al. (1994).

\section{Maintenance of stock culture for bacteria}

The stock culture was maintained following the procedures of Chowdhury et al. (1994). During the experiment it was necessary to preserve the isolated organisms for longer periods. For this purpose, pure culture of the isolated organisms were stored in sterilized $80 \%$ glycerin and used as stock culture. Equal volume of $80 \%$ glycerin and bacterial culture were mixed and sealed with paraffin wax and stored at $-20^{\circ} \mathrm{C}$ in refrigerator for future use. Isolates were given code name for convenience.

\section{RESULTS AND DISCUSSION}

Measurement of body weight of selected commercial broiler farms (Vai-Vai Poultry Farm, Israfil Poultry Farm, Guljar Poultry Farm and Maa Poultry Farm) were compared with standard body weight from table 1 and found the stunted growth of birds (Table 3). Mortality rate of commercial broilers also observed in the farm (Table 4).

Table 3. Measurement of Body weight of different farms compared with standard body weight

\begin{tabular}{|ccccccc|}
\hline S/N & Age of birds & $\begin{array}{c}\text { Standard avg. body } \\
\text { weight (gms) }\end{array}$ & \multicolumn{4}{c|}{ Measured average weight (gms) } \\
\cline { 3 - 6 } & & 165 & Farm 1 & Farm 2 & Farm 3 & Farm 4 \\
\hline 01. & $1-7^{\text {th }}$ day & 410 & 405 & 161 & 144 & 159 \\
02. & $1-14^{\text {th }}$ day & 745 & 738 & 739 & 352 & 401 \\
03. & $1-21^{\text {st }}$ day & 1025 & 1012 & 1011 & 683 & 739 \\
04. & $1-25^{\text {th }}$ day & 1850 & 1795 & 1799 & 1003 & 1009 \\
05. & $1-31^{\text {st }}$ day & & Satisfactory & Satisfactory & Unsatisfactory & Satisfactory \\
\hline & Remarks & & & (selected for study) & \\
\hline
\end{tabular}

Farm 1= Vai-Vai Poultry Farm Farm 2= Israfil Poultry Farm Farm 3= Guljar Poultry Farm Farm 4= Maa Poultry Farm.

\section{Cultural prevalence of microbes in Guljar Poultry Farm}

From the study the cultural prevalence of microbes in Guljar poultry farm for Fungi, E. coli and Salmonella were $16.07 \%, 66.07 \%$ and $46.42 \%$ respectively (Table 5). A total 09 samples were found positive for Fungi from 56 samples and prevalence of fungi was observed $16.07 \%$, slightly higher than Saleque et al (2003) due to differences of strain of birds and research was conducted under different environmental condition. Total 37 samples were found positive for E. coli from 56 samples and prevalence of E. coli was observed $66.07 \%$. The rate was close agreement with the findings of Mishra et al (2002) and lower than Derakhshantar and Ghanbarpour (2002). This may be due to different environmental, managemental condition, feed habit and mixed 


\section{M. Shah and others}

infection with other microbes. A total of 26 samples were positive for Salmonella out of 56 samples with a prevalence of salmonellosis as $46.42 \%$. The results were also evidenced by other authors (Biswas et al., 2004; Habib-ur- Rehman et al., 2004; Ahmed et al., 2007).

Table 4. Mortality rates of birds from selected commercial broiler farms

\begin{tabular}{|lcccc|}
\hline S/N & Farm 1 & Farm 2 & Farm 3 & Farm 4 \\
\hline $1-7^{\text {th }}$ day (dead of birds) & 05 & 07 & 08 & 07 \\
$1-14^{\text {th }}$ day(dead of birds) & 06 & 06 & 11 & 05 \\
$1-21^{\text {st }}$ day(dead of birds) & 05 & 06 & 13 & 05 \\
$1-30^{\text {th }}$ day(dead of birds) & 11 & 11 & 24 & 07 \\
Duration & 31.03 .2011 to & 18.04 .2011 to & 21.05 .2011 to & 25.06 .2011 to \\
& 29.04 .2011 & 17.05 .2011 & 19.06 .2011 & 29.07 .2011 \\
Total days of observation & 30 & 30 & 30 & 30 \\
Total birds & 900 & 600 & 700 & 600 \\
Total dead of birds & 27 & 30 & 56 & 24 \\
Mortality rate & $3 \%$ & $5 \%$ & $8 \%$ & $4 \%$ \\
\hline Remarks & Satisfactory & Satisfactory & Unsatisfactory & Satisfactory \\
\hline
\end{tabular}

Farm 1= Vai-Vai Poultry Farm Farm 2= Israfil Poultry Farm Farm 3= Guljar Poultry Farm Farm 4= Maa Poultry Farm

Table 5. Cultural prevalence of microbes in Guljar Poultry Farm

\begin{tabular}{|lccc|}
\hline S/ Microbes & $\begin{array}{c}\text { Total number of positive } \\
\text { samples tested from farm 3 }\end{array}$ & $\begin{array}{c}\text { No. of positive isolates } \\
\text { O1.Fungi }\end{array}$ & $\begin{array}{c}\text { Cultural prevalence of isolates } \\
(\%)\end{array}$ \\
\hline 02.E. coli & 56 & 09 & 16.07 \\
03.Salmonella & & $37^{*}$ & 66.07 \\
\hline
\end{tabular}

*Mixed infection (Salmonella and E. coli both)

\section{Morphology, cultural, staining and Biochemical characteristics of isolated $E$. coli}

In Gram's staining, the morphology of the isolated bacteria exhibited Gram negative (pink color) small rodshape, arranged in singly or paired or arranged on short chains which were supported by Buxton and Fraser, (1977) and Freeman (1985) (Table 6).

Table 6. Morphology, cultural characteristics and staining characteristics of isolated E. coli

\begin{tabular}{|lll|}
\hline \multicolumn{1}{|c}{ Media used } & \multicolumn{1}{c|}{ Colony characteristics } & \multicolumn{1}{c|}{$\begin{array}{c}\text { Morphology (staining } \\
\text { Characters) }\end{array}$} \\
\hline Salmonella-Shigella agar & Slight pink smooth colony. & $\begin{array}{l}\text { Gram negative short rod shaped } \\
\text { singly or paired arranged on } \\
\text { short chain }\end{array}$ \\
MacConkey's agar & $\begin{array}{l}\text { Bright, pink colored transparent smooth raised } \\
\text { colony. }\end{array}$ \\
Eosin methylene blue agar & $\begin{array}{l}\text { Yellow green characteristic metallic sheen. } \\
\text { Nutrient agar }\end{array}$ & $\begin{array}{l}\text { Circular, smooth, colorless colonies } \\
\text { Nutrient broth }\end{array}$ \\
\hline
\end{tabular}

In the present study, biochemical tests which were used for characterization of bacterial pathogens were supported by Freeman (1985) and Ali et al. (2004). E. coli produced acid and gas by fermenting various sugars and gave positive reaction to Indole, Motility Indole Urease, Methyl red test but negative reaction to Voges Proskauer test which satisfy the statement of Buxton and Fraser (1977) (Table 7). 
Table 7. Biochemical characteristics of E. coli

CHO fermentation and other biochemical tests

Dextrose fermentation

Lactose fermentation

Sucrose fermentation

Mannitol fermentation

Indole production

Methyl Red test

Voges-Proskauer test

Triple Sugar Iron

Butt

Slant

Result
+
+
+
+
+
+
-
Yellow
Yellow
+

Hydrogen sulphide gas

$+=$ Positive $-=$ Negative

\section{Morphology, cultural, staining and biochemical characteristics of isolated Salmonella spp.}

In Gram's staining, the morphology of the isolated bacteria exhibited Gram negative (pink color) short rod shape, arranged in singly or short chains which were supported by Buxton and Fraser, (1977) and Freeman (1985) (Table 8).

In the present study, biochemical tests used for characterization of bacterial pathogens were supported by Freeman (1985). Salmonella spp. produced acid and gas by fermenting various sugars and gave negative reaction to Indole, Motility Indole Urease and Voges Proskauer test but positive to Methyl red and test which satisfy the statement of Buxton and Fraser (1977) (Table 9).

Table 8. Morphology, cultural and staining characteristics of isolated Salmonella spp

\begin{tabular}{|lll|}
\hline \multicolumn{1}{|c|}{ Media used } & Colony characteristics & Staining Characteristics \\
\hline Salmonella-Shigella agar & Opaque translucent colorless smooth round colonies. & \\
MacConkey's & Pale, Colorless, smooth, transparent, raised colonies & \\
agar & Pale pink color colonies against a yellowish & $\begin{array}{l}\text { Gram negative short rod shaped } \\
\text { singly arranged }\end{array}$ \\
Brilliant green agar & background. & \\
TSI agar & Transparent, smooth round colonies \\
Nutrient agar & Translucent, opaque, smooth colonies \\
Nutrient broth & Turbidity in the broth & \\
\hline
\end{tabular}

Table 9. Biochemical characteristics of Salmonella spp

\begin{tabular}{|c|c|c|}
\hline \multicolumn{2}{|c|}{ CHO fermentation and other biochemical tests } & Result \\
\hline \multicolumn{2}{|c|}{\begin{tabular}{|c|} 
Dextrose fermentation \\
\end{tabular}} & + \\
\hline \multicolumn{2}{|c|}{ Lactose fermentation } & - \\
\hline \multicolumn{2}{|c|}{ Sucrose fermentation } & - \\
\hline \multicolumn{2}{|c|}{ Mannitol fermentation } & + \\
\hline \multicolumn{2}{|c|}{ Indole production } & - \\
\hline \multicolumn{2}{|c|}{ Methyl Red test } & + \\
\hline \multicolumn{2}{|c|}{ Voges-Proskauer test } & - \\
\hline \multirow{3}{*}{ Triple Sugar Iron } & Butt & Yellow \\
\hline & Slant & Red \\
\hline & Hydrogen sulphide gas & + \\
\hline
\end{tabular}

$+=$ Positive $-=$ Negative 


\section{M. Shah and others}

However, for useful application of the present research findings further studies should be conducted on molecular and antigenic characterization of identified field isolates of Salmonella spp. and Escherichia coli, development of vaccines and determination of pathogenicity of identified microbes associated with stunted growth of commercial broiler birds.

\section{REFERENCES}

1. Ahmed W, Tucker J, Bettelheim KA, Neller R and Katouli M (2007). Detection of virulence genes in Escherichia coli of an existing metabolic fingerprint database to predict the sources of pathogenic Escherichia coli in surface waters. Water Research 41: 3785-3791.

2. Ali MY, Rahman MT, Islam MA, Choudhury KA and Rahman MA (2004). Characteristics of Escherichia coli isolates of human and animal origin. Progressive Agriculture 9: 221-224.

3. Biswas PK, Rahman MA and Ahmed S (2004). A longitudinal study on the prevalence of endemic diseases affecting semi-scavenging poultry reared under PLDP area. Ninth BSVER annual Scientific Conference held at Bangladesh Agricultural University, Mymensingh on 6-7 January, 2003 BSVER Publication No. 24. pp. 24-25.

4. Chowdhury MA, Rahman KM, Miah MR and Haq JA (1994). Transferable drug resistance (R-factor) among the enterobacteriaceae in urinary tract infections: a study at an urban hospital in Bangladesh. Journal of Tropical Medicine and Hygiene 97: 161-166.

5. Buxton A and Fraser G (1977). Animal Microbiology. Vol. 1. Blackwell Scientific Publications, Oxford, London, Edinburg Melbourne. Pp. 103-115.

6. Cowan ST (1985). Cowan and Steel's Manual for Identification of Medical Bacteria. $2^{\text {nd }}$ edition. Cambridge University Press, Cambridge, London, pp. 138-139.

7. Derakhshanter A and Ghanbarpour R (2002). A study on avian cellulites in broiler chickens. Veterinarski Archiv 72: 277-284.

8. Freeman BA (1985). Burrows Textbook of Microbiology. $22^{\text {nd }}$ edn. In: Gay CC and Besser TE (1994). Escherichia coli septicaemia in calves. CAB international Wallingford, pp. 75.

9. Habib-ur- Rehman S, Mustak A and Rahim BK (2004). Incidence and Gross pathology of Salmonella gallinarum infection in chicken. Journal of Animal and Veterinary Advances 3 (3): 175-178.

10. Haider MG, Hossain MG, Hossain MS, Chowdhury EH, Das PM and Hossain MM (2004). Isolation and characterization of enterobacteria associated with health and disease in sonali chickens. Bangladesh Journal of Veterinary Medicine 2: 15-21.

11. Haque ME, Hamid MA, Howleder MAR and Haque QME (1991). Performance of native chicks and hens reared together or separately under rural condition in Bangladesh. Bangladesh Veterinarian 8: 11-13.

12. Merchant IA and Packer RA (1967). Veterinary Bacteriology and Virology. $7^{\text {th }}$ edn. The Iowa University Press, Ames, Iowa, USA. pp. 286-306.

13. Mishra A, Shards R, Chhabra D and Moghe MN (2002). Escherichia coli isolated from domestic poultry farm. Indian Journal of Animal Sciences 72: 727-729.

14. Otaki Y (1995). Poultry disease control programme in Japan. Asian Livestock 20: 65-67.

15. Rippon JW (1988). Medical Mycology. $3^{\text {rd }}$ edition. pp. 618-646.

16. Saleque MA, Rahman MH and Hossain MI (2003). Seasonal variation in the prevalence of poultry diseases in Bangladesh. Ninth BSVER annual Scientific Conference held in BAU, Mymensingh on 6-7 January, 2003 BSVER publication. 24:23-24.

17. Samad MA (2005). Poultry Science and Medicine. $1^{\text {st }}$ Pub., LEP No. 10, BAU Campus, Mymensingh, Bangladesh.

18. Scurter EA, Deterson CF, Steele EE, Parkinson JF, Dixon JE and Stroh RC (1981). The airborne microflora of poultry houses. British Poultry Science 60:569-574. 